\title{
Handedness genetics: considering the phenotype
}

\author{
Sebastian Ocklenburg ${ }^{1}{ }^{*}$, Christian Beste ${ }^{2}$ and Larissa Arning ${ }^{3}$ \\ ${ }^{1}$ Biopsychology, Institute of Cognitive Neuroscience, Ruhr-University Bochum, Bochum, Germany \\ ${ }^{2}$ Cognitive Neurophysiology, Department of Child and Adolescent Psychiatry, Faculty of Medicine, Dresden University of Technology, Dresden, Germany \\ ${ }^{3}$ Department of Human Genetics, Ruhr-University Bochum, Bochum, Germany \\ *Correspondence: sebastian.ocklenburg@rub.de
}

Edited by:

Pamela Bryden, Wilfrid Laurier University, Canada

Reviewed by:

Uner Tan, Cukurova University, Turkey

Michael Charles Corballis, University of Auckland, New Zealand

Chris McManus, University College London, UK

Keywords: handedness, genotype, phenotype, laterality, hemispheric asymmetry, hemispheric lateralization, motor control, ontogenesis

The question which genetic, epigenetic and environmental factors contribute to human handedness certainly is one of the central questions in research on manual asymmetries. A number of environmental factors such as season of birth (Stoyanov et al., 2011), cultural influences (Fagard and Dahmen, 2004), differential visual experience of the hands (Ocklenburg and Güntürkün, 2009; Ocklenburg et al., 2010), parental influence (Laland, 2008) and others (Schaafsma et al., 2009) have been shown to influence handedness. Moreover, several genes such as LRRTM1 (Francks et al., 2007), PCSK6 (Scerri et al., 2011; Arning et al., 2013), and AR (Medland et al., 2005; Hampson and Sankar, 2012) have been related to handedness. However, the variance in individual handedness explained by any single one of these factors is typically low, and it is not uncommon that findings in one sample cannot be replicated in others (for example see: Bloss et al., 2010; Hubacek et al., 2013). Furthermore, hardly anything is known about epigenetic and epistatic interactions between different genetic and environmental factors influencing handedness. In view of this, several authors recently argued that only a complex multifactorial model could explain the ontogenesis of handedness (e.g., McManus et al., 2013; Ocklenburg et al., 2013; Armour et al., 2014). McManus et al. (2013) estimated the number of genetic loci involved in handedness to be at least 30-40, and possibly much larger. This estimation suggests that genome-wide association studies with very large sample sizes might constitute a meaningful methodological tool to further advance our knowledge about how handedness develops. In our opinion, however, the large number of involved ontogenetic factors and likely complex interactions between them is only part of the problem why the search for the biological determinants involved in the development of handedness despite continuous research still is at a very early stage.

While a definition of handedness seems trivial at first glance, the term "handedness" actually has been used to describe a number of surprisingly different concepts, rendering clarification necessary. First, as discussed in a recent review article by Scharoun and Bryden (2014), there is an important distinction between hand preference and hand performance. Hand preference commonly is assessed with questionnaires such as the widely used Edinburgh Handedness Inventory (EHI, Oldfield, 1971). The EHI identifies an individual's subjectively preferred hand for 10 different manual activities (e.g., writing or striking a match). A lateralization quotient (LQ) is calculated using the formula $\mathrm{LQ}=[(\mathrm{R}-\mathrm{L}) /(\mathrm{R}+\mathrm{L})]^{*} 100$, with $\mathrm{R}$ indicating the number of activities for which the right hand is preferentially used, and $\mathrm{L}$ indicating the number of activities for which the left hand is preferentially used. The LQ ranges between -100 and +100 , with negative values indicating a larger number of left-hand preferences, and positive values indicating a larger number of right-hand preferences. While some authors developed behavioral approaches to assess hand preference (e.g., Calvert and Bishop, 1998), the overwhelming majority of researchers uses questionnaires such as the EHI to assess hand preference.

Hand performance, on the other hand, typically is assessed with motor tasks such as the widely used peg board task (e.g., Annett, 1985, 2002; Scerri et al., 2011). In this task, the time participants need to move a row of 10 pegs from one side of a board to the other is measured. A quantitative value of asymmetry in hand performance is obtained by comparing reaction times for left and right hand. Other hand performance tasks include placing dots in circles or squares on a sheet of paper as quickly as possible (McManus, 1985; Tapley and Bryden, 1985), or picking up 20 matches placed on a table as quickly as possible (McManus, 1985). Interestingly, tests of hand preference and hand performance yield significantly different distributions (Peters and Durding, 1978; Nicholls et al., 2010). Hand preference typically has a J-shaped (and hence bimodal) distribution with a large number of strongly right-handed individuals, a smaller number of strongly left-handed individuals, and few individuals in between, e.g., ambidextrous to some degree, and some authors have argued that handedness in fact is a dichotomous variable (e.g., McManus, 2002; also see Corballis et al., 2012 for an overview).

In contrast, hand performance measured with the peg board task typically shows a more unimodal distribution with a shift to the right side (Annett, 1985). However, McManus (1985) has argued that the peg board data are also bimodal, and that the assumed unimodality might be an artifact of measurement noise, since 
a high amount of noise in the data could make it possible that a smaller distribution of left-handers is hidden in the tail of the larger distribution of the right-handers. While the details of this discussion go beyond the scope of this Opinion article, it is also important to mention that the distribution of hand performance data seems to be task-dependent to a large extent, with some tasks (e.g., McManus, 1985; Tapley and Bryden, 1985) clearly showing more bimodal distributions than the peg board task.

Although hand performance and hand preference seem to be related, the correlation between them strongly depends on the tasks used to assess the two parameters. For example, while Badzakova-Trajkov et al. (2011) found a strong correlation between hand preference and hand performance scores $(r=0.72)$, a recent study by Geuze et al. (2012), reported much lower correlation coefficients. In this study, the correlation between hand preference and peg board performance was 0.09 , while it was 0.03 for hand preference and grip force, and 0.19 for hand preference and ball throwing accuracy. Moreover, even though the correlations with peg board task performance and ball throwing accuracy reached significance, none of the correlation coefficients indicated a particularly strong association. While the striking difference between the two studies may be partly due to differential percentages of left- and right-handers in the two samples (in the Badzakova-Trajkov et al., 2011, sample there were 23 lefthanded, 48 mixed-handed and 64 righthanded participants while in the Geuze et al., 2012, sample there were 15 lefthanded, 8 mixed-handed and 598 righthanded participants) there is clearly more research on the complex relation of hand preference and hand performance needed. Interestingly, it has also been shown that hand preference correlates with certain cognitive variables, like magical ideation and creative achievement, while hand performance does not (Badzakova-Trajkov et al., 2011). Taken together, these findings suggest that what is considered as handedness by different studies is not a uniform trait but might represent several different, distinct phenotypes.

This idea is also supported by the distinction of handedness direction and handedness consistency. Handedness direction is usually defined as the side of the preferred hand for fine motor activities, e.g., left-handed or righthanded, although some authors also use "mixed-handed" as a third category. This practice, however, has been strongly criticized by McManus (1996) who argued that mixed-handedness does not represent a natural category but rather a mixture of weak left-handers and weak right-handers. Instead, McManus (1996) suggests using a subdivision into four handedness groups (weak right, strong right, weak left, strong left) when further differentiation of handedness direction is desired. In contrast to direction, handedness consistency (some authors also use the term "handedness degree," e.g., by Prichard et al., 2013) is the specificity of the preference for using one hand over the other, e.g., if one hand is used for all task as opposed to one hand being used for some tasks and the other hand for others. Both handedness direction and handedness consistency can be calculated based on results of a handedness preference questionnaire or a handedness performance task.

Interestingly, Arning et al. (2013) demonstrated that a sequence variation (rs10523972) in PCSK6 was significantly associated with handedness consistency but not with handedness direction. Individuals heterozygous for a long and a short allele of an intronic 33 bp variablenumber tandem repeat polymorphism were more prone to inconsistent hand preference (e.g., performing most-but not all-tasks with one hand) than individuals homozygous for a long allele. In contrast, no association between this polymorphism and handedness direction was observed. It is therefore likely that handedness direction and consistency (or strength) represent distinct phenotypes. This idea is also supported by several studies showing that handedness consistency, but not handedness direction, is a systematic predictor of performance in several cognitive domains, e.g. episodic memory retrieval, cognitive flexibility and risk perception (see Prichard et al., 2013 for a comprehensive review article).

Interestingly, the view that direction and strength of hemispheric asymmetries represent two distinct, largely independent phenotypes is also supported by recent studies in zebrafish. In this species, behavioral lateralization is modulated by structural asymmetries in the epithalamus (Barth et al., 2005; Bianco and Wilson, 2009). Genetically, the occurrence of these epithalamic asymmetries is regulated by several genes within the NODAL pathway which generally is relevant for the determination of left-right asymmetry in embryonic development. When expression of this pathway is symmetrical or absent, structural asymmetry per se is still established but its direction is not leftward like in most wildtype fish, but completely random (Concha et al., 2000). Thus, strength and direction of these hemispheric asymmetries in zebrafish likely are controlled for by two different genetic pathways. This finding is particularly interesting since Brandler and Paracchini (2014) recently suggested the NODAL pathway to also be involved in the ontogenesis of human handedness.

Taken together, in our opinion the large number of possibly interacting genes and non-genetic factors is only one reason why it is so difficult to determine the ontogenetic bases of handedness and other forms of hemispheric asymmetries. Another reason is that we simply do not know enough about what exactly constitutes a handedness phenotype, and how many there are. For the time being, we would like to suggest that future studies on the genetics of hemispheric asymmetries should include both a preference measure (e.g., EHI) and a performance measure (e.g., the peg board task), and that both direction and strength should be reported for those two measures in addition to a composite score such as a laterality quotient. Furthermore, research on the genetics of handedness may benefit from a stronger integration of brain activation measures, e.g., motor cortex activation differences between leftand right-handers during finger tapping or similar tasks.

\section{REFERENCES}

Annett, M. (1985). Left, Right, Hand and Brain: the Right Shift Theory. Hillsdale, NJ: Lawrence Erlbaum Associates.

Annett, M. (2002). Handedness and Brain Asymmetry: the Right Shift Theory. Hove: Psychology Press.

Armour, J. A., Davison, A., and McManus, I. C. (2014). Genome-wide association study of handedness excludes simple genetic models. Heredity 112, 221-225. doi: 10.1038/hdy.2013.93 
Arning, L., Ocklenburg, S., Schulz, S., Ness, V., Gerding, W. M., Hengstler, J. G., et al. (2013). PCSK6 VNTR polymorphism is associated with degree of handedness but not direction of handedness. PLoS ONE 8:e67251. doi: 10.1371/journal.pone.0067251

Badzakova-Trajkov, G., Häberling, I. S., and Corballis, M. C. (2011). Magical ideation, creativity, handedness, and cerebral asymmetries: a combined behavioural and fMRI study. Neuropsychologia 40, 2896-2903. doi: 10.1016/j.neuropsychologia.2011.06.016

Barth, K. A., Miklosi, A., Watkins, J., Bianco, I. H., Wilson, S. W., and Andrew, R. J. (2005). fsi zebrafish show concordant reversal of laterality of viscera, neuroanatomy, and a subset of behavioral responses. Curr. Biol. 15, 844-850. doi: 10.1016/j.cub.2005.03.047

Bianco, I. H., and Wilson, S. W. (2009). The habenular nuclei: a conserved asymmetric relay station in the vertebrate brain. Philos. Trans. R. Soc. Lond. B Biol. Sci. 364, 1005-1020. doi: 10.1098/rstb.2008.0213

Bloss, C. S., Delis, D. C., Salmon, D. P., and Bondi, M. W. (2010). APOE genotype is associated with left-handedness and visuospatial skills in children. Neurobiol. Aging 31, 787-795. doi: 10.1016/j.neurobiolaging.2008.05.021

Brandler, W. M., and Paracchini, S. (2014). The genetic relationship between handedness and neurodevelopmental disorders. Trends Mol. Med. 20, 83-90. doi: 10.1016/j.molmed.2013.10.008

Calvert, G. A., and Bishop, D. V. (1998). Quantifying hand preference using a behavioural continuum. Laterality 3, 255-268. doi: 10.1080/713754307

Concha, M. L., Burdine, R. D., Russell, C., Schier, A. F., and Wilson, S. W. (2000). A nodal signaling pathway regulates the laterality of neuroanatomical asymmetries in the zebrafish forebrain. Neuron 28, 399-409. doi: 10.1016/S0896-6273(00)00120-3

Corballis, M. C., Badzakova-Trajkov, G., and Häberling, I. S. (2012). Right hand, left brain: genetic and evolutionary bases of cerebral asymmetries for language and manual action. WIRES Cog. Sci. 3, 1-17. doi: 10.1002/wcs. 158

Fagard, J., and Dahmen, R. (2004). Cultural influences on the development of lateral preferences: a comparison between French and Tunisian children. Laterality 9, 67-78. doi: 10.1080/13576500342000167

Francks, C., Maegawa, S., Laurén, J., Abrahams, B. S., Velayos-Baeza, A., Medland, S. E., et al. (2007). LRRTM1 on chromosome $2 \mathrm{p} 12$ is a maternally suppressed gene that is associated paternally with handedness and schizophrenia. Mol. Psychiatry 12, 1129-1139. doi: 10.1038/sj.mp.4002053

Geuze, R. H., Schaafsma, S. M., Lust, J. M., Bouma, A., Schiefenhövel, W., and Groothuis, T. G. (2012). Plasticity of lateralization: schooling predicts hand preference but not hand skill asymmetry in a nonindustrial society. Neuropsychologia 50, 612-620. doi: 10.1016/j.neuropsychologia.2011.12.017

Hampson, E., and Sankar, J. S. (2012). Hand preference in humans is associated with testosterone levels and androgen receptor gene polymorphism. Neuropsychologia 50, 2018-2025. doi: 10.1016/j.neuropsychologia.2012.04.027

Hubacek, J. A., Piper, B. J., Pikhart, H., Peasey, A., Kubinova, R., and Bobak, M. (2013). Lack of an association between left-handedness and APOE polymorphism in a large sample of adults: results of the Czech HAPIEE study. Laterality 18, 513-519. doi: 10.1080/1357650X.2012.715164

Laland, K. N. (2008). Exploring gene-culture interactions: insights from handedness, sexual selection and niche-construction case studies. Philos. Trans. R. Soc. Lond. B Biol. Sci. 363, 3577-3589. doi: 10.1098/rstb.2008.0132

McManus, I. C. (1985). Right- and left-hand skill: failure of the right shift model. Br. J. Psychol. 76, 1-34. doi: 10.1111/j.2044-8295.1985.tb01926.x

McManus, I. C. (1996). "Handedness," in The Blackwell Dictionary of Neuropsychology, eds J. G. Beaumont, P. M. Kenealy, and M. J. C. Rogers, (Oxford: Blackwell), 367-376.

McManus, I. C. (2002). Right Hand, Left Hand. London: Weidenfeld \& Nicolson.

McManus, I. C., Davison, A., and Armour, J. A. (2013). Multilocus genetic models of handedness closely resemble single-locus models in explaining family data and are compatible with genomewide association studies. Ann. N.Y. Acad. Sci. 1288, 48-58. doi: 10.1111/nyas. 12102

Medland, S. E., Duffy, D. L., Spurdle, A. B., Wright, M. J., Geffen, G. M., Montgomery, G. W., et al. (2005). Opposite effects of androgen receptor CAG repeat length on increased risk of left-handedness in males and females. Behav. Genet. 35, 735-744. doi: 10.1007/s10519-005-6187-3

Nicholls, M. E., Chapman, H. L., Loetscher, T., and Grimshaw, G. M. (2010). The relationship between hand preference, hand performance, and general cognitive ability. J. Int. Neuropsychol. Soc. 16, 585-592. doi: 10.1017/S1355617710000184

Ocklenburg, S., Bürger, C., Westermann, C., Schneider, D., Biedermann, H., and Güntürkün, O. (2010). Visual experience affects handedness. Behav. Brain Res. 207, 447-451. doi: 10.1016/j.bbr.2009.10.036

Ocklenburg, S., Beste, C., and Güntürkün, O. (2013). Handedness: a neurogenetic shift of perspective. Neurosci. Biobehav. Rev. 37, 2788-2793. doi: 10.1016/j.neubiorev.2013.09.014

Ocklenburg, S., and Güntürkün, O. (2009). Headturning asymmetries during kissing and their association with lateral preference. Laterality 14, 79-85. doi: 10.1080/13576500802243689
Oldfield, R. C. (1971). The assessment and analysis of handedness: the Edinburgh inventory. Neuropsychologia 9, 97-113. doi: 10.1016/00283932(71)90067-4

Peters, M., and Durding, B. M. (1978). Handedness measured by finger tapping: a continuous variable. Can. J. Psychol. 32, 257-261. doi: 10.1037/h0081694

Prichard, E., Propper, R. E., and Christman, S. D. (2013). Degree of handedness, but not direction, is a systematic predictor of cognitive performance. Front. Psychol. 4:9 doi: 10.3389/fpsyg.2013. 00009

Scerri, T. S., Brandler, W. M., Paracchini, S., Morris, A. P., Ring, S. M., Richardson, A. J., et al. (2011). PCSK6 is associated with handedness in individuals with dyslexia. Hum. Mol. Genet. 20, 608-614. doi: 10.1093/hmg/ddq475

Scharoun, S. M., and Bryden, P. J. (2014). Hand preference, performance abilities, and hand selection in children. Front. Psychol. 5:82. doi 10.3389/fpsyg.2014.00082

Schaafsma, S. M., Riedstra, B. J., Pfannkuche, K. A., Bouma, A., and Groothuis, T. G. (2009). Epigenesis of behavioural lateralization in humans and other animals. Philos. Trans. R. Soc. Lond. B Biol. Sci. 364, 915-927. doi: 10.1098/rstb.2008.0244

Stoyanov, Z., Nikolova, P., and Pashalieva, I. (2011). Season of birth, Geschwind and Galaburda hypothesis, and handedness. Laterality 16, 607-619. doi: 10.1080/1357650X.2010.506689

Tapley, S. M., and Bryden, M. P. (1985). A group test for the assessment of performance between the hands. Neuropsychologia 23, 215-221. doi: 10.1016/0028-3932(85)90105-8

Conflict of Interest Statement: The authors declare that the research was conducted in the absence of any commercial or financial relationships that could be construed as a potential conflict of interest.

Received: 05 September 2014; accepted: 26 October 2014; published online: 11 November 2014.

Citation: Ocklenburg S, Beste C and Arning L (2014) Handedness genetics: considering the phenotype. Front. Psychol. 5:1300. doi: 10.3389/fpsyg.2014.01300

This article was submitted to Movement Science and Sport Psychology, a section of the journal Frontiers in Psychology.

Copyright (C) 2014 Ocklenburg, Beste and Arning. This is an open-access article distributed under the terms of the Creative Commons Attribution License (CC BY). The use, distribution or reproduction in other forums is permitted, provided the original author(s) or licensor are credited and that the original publication in this journal is cited, in accordance with accepted academic practice. No use, distribution or reproduction is permitted which does not comply with these terms. 